\title{
Phylogeography of a widespread terrestrial vertebrate in a barely- studied Palearctic region: green toads (Bufo viridis subgroup) indicate glacial refugia in Eastern Central Asia
}

\author{
Yi-Jun Zhang · Matthias Stöck · Peng Zhang · Xiu-Ling Wang • \\ Hui Zhou · Liang-Hu Qu
}

Received: 29 September 2007 / Accepted: 27 January 2008/Published online: 27 February 2008

(C) Springer Science+Business Media B.V. 2008

\begin{abstract}
The phylogeography of western Palearctic species is relatively well studied, but data on Eastern Central Asia are scarce. We present one of the first data sets from a widespread terrestrial vertebrate (Bufo pewzowi) inhabiting Eastern Central Asian mountains and deserts to gain knowledge on its phylogeography in this region. We applied combined phylogenetic and demographic analyses to understand the evolutionary history using mitochondrial DNA D-loop variation of toads from 37 locations. Genetic structure of Bufo pewzowi is strongly affected by landscape: we found three haplotype groups in eastern Kazakhstan, Dzungaria and Tarim Basin, divided by the Tian Shan and Dzungarian Alatau ranges. A vicariant hypothesis may
\end{abstract}

Y.-J. Zhang · P. Zhang · H. Zhou · L.-H. Qu ( $ه)$

Key Laboratory of Gene Engineering of the Ministry of

Education, Biotechnology Research Center, Zhongshan

University, Guangzhou 510275, P.R. China

e-mail: 1ssqlh@mail.sysu.edu.cn; zayiju@126.com

Present Address:

P. Zhang

Department of Integrative Biology, Museum of Vertebrate

Zoology, University of California, 3101 Valley of Life Sciences

Building, Berkeley, CA 94720-3160, USA

e-mail: alarzhang@berkeley.edu

\section{Stöck}

Department of Integrative Biology, Museum of Vertebrate

Zoology, University of California, 3101 Valley of Life Sciences

Building, Berkeley, CA 94720-3160, USA

e-mail: matthias.stoeck@unil.ch

Present Address:

M. Stöck

Department of Ecology and Evolution, University of Lausanne,

Biophore, 1015 Lausanne, Switzerland

X.-L. Wang

Department of Biology, Xinjiang Normal University,

Xinjiang 830054, P.R. China explain divergence among groups. The divergence time of the three major clades was estimated about 0.9 million years ago (confidence interval 0.5-1.4), and is discussed with respect to Quaternary uplifting and glaciation in the Tian Shan. Demographic analyses provided evidence for both historical bottlenecks and population expansions and suggested Pleistocene signatures. Glacial refugia were inferred in the Tarim Basin (around the Turpan depression), in southern Dzungaria (Urumqui region), at the northern foot of the Tian Shan (Gongnaisi) and perhaps at the Altai range (Terekti). Regional Post-Last Glacial Maximum dispersal patterns are proposed. A taxonomic hypothesis is presented. This study provides a detailed history of how a widespread terrestrial vertebrate responded to geological change and Quaternary glacial events in Eastern Central Asia and may have significance for future phylogeographic research in this understudied region.

Keywords D-loop · Eastern Central Asia - Glacial refugia - Green toads - Historical biogeography . phylogeography $\cdot$ Post glacial expansion

\section{Introduction}

While the phylogeography of terrestrial species in the northwestern Palearctic is relatively well studied (reviews: Hewitt 2000, 2004; Petit et al. 2003; Taberlet et al. 1998), data from Central Asia are extremely scarce: "The extent of our knowledge of the Holarctic is considerable for Europe and North America, but Asia is little studied, and so too the deserts..." (Hewitt 2007). It can be assumed, however, that orogenic history and Pleistocene climatic oscillations have also affected the geographic distributions, demography, and thus evolution of species in Central Asia. Its complex 
landscape history includes the dramatic high mountain formations initiated by the Indian collision (starting 70 Mya), the formation of the Paleozoic Dzungarian basin, and the construction of the Cenozoic Tibetan plateau (50-40 Mya) with the Himalaya in the south, and the Kunlun Shan and the Qilian Shan in the north (Yin and Harrison 2000). In the Cenozoic, also the Tarim Basin developed as a complex foreland basin in association with mountain building in Tibet and Tian Shan (Yang and Liu 2002). At least four main Quaternary glaciations were detected in the Tian Shan (Shi 2002). The early Pleistocene glaciation history of some central regions is not well understood (Ehlers 2004; Lehmkuhl and Strauch 2004). During Middle and Late Pleistocene, the permafrost of the northern and central plains of Kazakhstan merged with the permafrost of the mountains in the south (Aubekerov and Gorbunov 1999), but island patterns of permafrost may have left refugia. During the last glacial maximum, permafrost came down to $\sim 900 \mathrm{~m}$ a.s.l. (Aubekerov and Gorbunov 1999) in Kazakhstan but only reached $\sim 1800 \mathrm{~m}$ a.s.l. in the Tarim Basin (Yang et al. 2002) suggesting larger refugia in the latter. Climate changes correlated with glacial cycles influenced distribution of regional faunas (e.g., Hewitt 2000). However, the phylogeography of terrestrial species in Eastern Central Asia including the Tarim Basin (with the Taklamakan Desert) and Dzungaria has been scarcely studied. The few examples on poikilothermic vertebrates come from phylogenetics in Teratoscincus (Macey et al. 1999, 2005) and Phrynocephalus lizards (Pang et al. 2003; Wang and Fu 2004; Guo and Wang 2007), lacking an explicit phylogeographic focus but indicated the barrier effect of the Tian Shan, and showed Dzungaria to be colonized from the West (Wang and $\mathrm{Fu}$ 2004). Among mammals, phylogeography of red deer (Cervus elaphus; Mahmut et al. 2002; Ludt et al. 2004) has revealed a major genetic difference between Tarim Basin and Dzungarian populations, with the western Tarim clade being more closely related to European populations and the lineages from Eastern Tarim, Tian Shan and Dzungaria showing relationship to East Asian and American ones. Recently, a study in Rhombomys gerbils (Ning et al. 2007) detected a separation (93 ka ago) of Dzungarian from Mongolian populations and assumed a population expansion about $12 \mathrm{ka}$. None of these studies attempted to test for the occurrence of glacial refugia in Eastern Central Asia. To our knowledge, no other phylogeographic studies have been conducted on other widespread terrestrial vertebrates. Therefore, phylogeographic insights from terrestrial species, as bufonid frogs, from this region can be of interest for the knowledge on the climatic history and biogeography of its range as well as for that species' biology.

Green toads (Bufo viridis subgroup) are widespread in the Palearctic including northwestern China and western
Mongolia (Borkin 1999; Stöck et al. 2006). The B. viridis subgroup is the only known amphibian species complex that comprises diploid, triploid and tetraploid bisexually reproducing taxa (Stöck et al. 2005). Bufo pewzowi (Bedriaga 1898) is a tetraploid member distributed in Central Asia, including Xinjiang (China), western Mongolia, and the entire Tian Shan range of Kazakhstan and Kyrgyzstan (Stöck et al. 2001). Only few previous studies have looked at genetic variation in the B. viridis subgroup (Liu et al. 2000; Nevo et al. 1975; Stöck et al. 2005). To study mitochondrial relationships of diploids to infer their phylogeography and the maternal ancestry of polyploids, Stöck et al. (2006) put a cytogenetic dataset from western and northeastern Central Asia in a molecular framework (mtDNA) and applied phylogenetic and demographic methods. However, only few data from Eastern Central Asia were available for that study.

Here we aimed to study how geological history and Pleistocene glaciation of temperate Eastern Central Asia influenced the genetic structure of $B$. pewzowi by testing two alternative hypotheses: (1) the species invaded the Tarim Basin and Dzungaria very recently after the last glacial maximum (LGM) and would therefore represent a scarcely structured group or (2) it had glacial refugia in one or both basins and spread from these into its large range during more favorable climatic conditions and therefore shows detectable phylogenetic structure.

For this purpose, we sequenced a fragment of the mitochondrial DNA (mtDNA) D-loop in toads sampled from throughout the species range in China and Eastern Kazakhstan, and analyzed their genealogy and demography.

\section{Materials and methods}

\section{Sample collection}

Samples from 37 localities across the entire species distribution range were obtained in the field or from existing collections (Fig. 1, Table 1). Samples (toe clips preserved in 95\% ethanol) from Xinjiang were collected in 2004. Samples from Kazakhstan and in part from Xinjiang (blood and muscle, preserved in ethanol) were collected in 1996 or were available from the frozen tissue collection of the Museum of Vertebrate Zoology (MVZ, University of California, Berkeley).

DNA extraction and sequencing of the mitochondrial control region

Genomic DNA was extracted following a standard phenol/ chloroform technique (Sambrook et al. 1989) or with the 


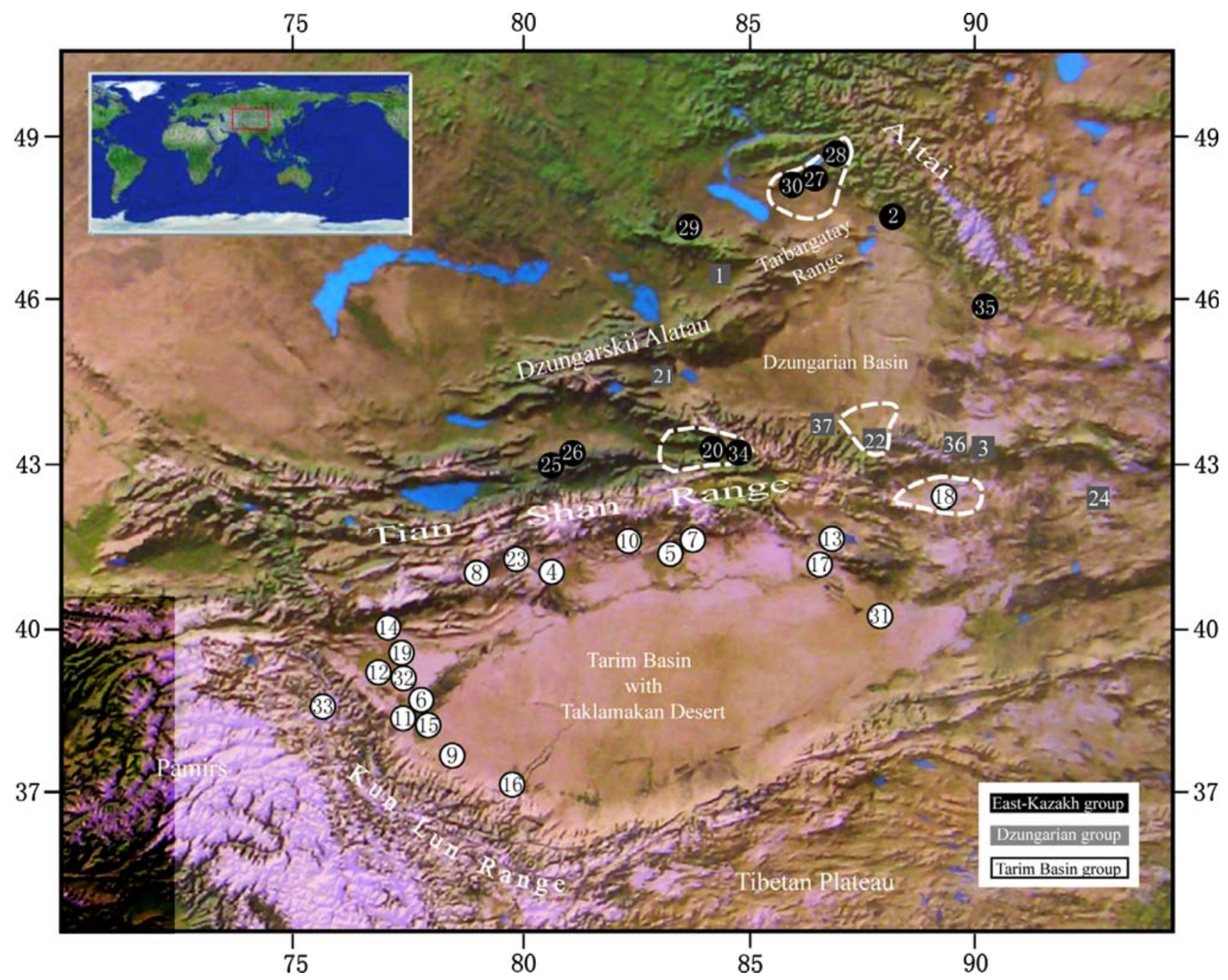

Fig. 1 Map of East Central Asia containing geographical features and localities of samples for this study. The numbers correspond to location numbers listed in Table 1. Haplotype group assignments for

Qiagen DNeasy ${ }^{\mathrm{TM}}$ kit. Partial mitochondrial D-loop was amplified in two thirds of the samples with the selfdesigned primer FCM (5'-GATTAAGCTATR TRAGTCCATAGATTC- $3^{\prime}$ ) and the published primer CytbA-L (5'-GAATYGGRGGWCAACCAGTAGAAGACCC-3'; Goebel et al. 1999); with ControlB-H and CytbA-L (Goebel et al. 1999) in the remaining. The PCRs $(20 \mu \mathrm{l})$ were carried out using standard conditions: $2.0 \mathrm{mM}$ $\mathrm{MgCl}_{2}, 0.5 \mathrm{mM}$ dNTPs, 1 unit ExTaq DNA polymerase (TAKARA), $0.75 \mu \mathrm{M}$ of each primer, and approximately 50 ng DNA. After 3 min of initial denaturation, each of 30 cycles consisted of the following steps: $94^{\circ} \mathrm{C}$ for $1 \mathrm{~min}$, $50^{\circ} \mathrm{C}$ for $1 \mathrm{~min}$, and $72^{\circ} \mathrm{C}$ for $2 \mathrm{~min}$, followed by a $10 \mathrm{~min}$ final extension at $72^{\circ} \mathrm{C}$. PCR products were purified using the QIAGEN purification kit and sequenced in one direction with the primer FCM on an ABI 377 Genetic Analyzer. Products from CytbA-L and ControlB-H PCRs populations based on phylogenetic analysis and likely glacial refugia (dashed circles) are shown. Relative position of this area is shown on the top left corner

were obtained and sequenced as described (Stöck et al. 2006). All sequences were checked with SeqMan (implemented in DNAStar software package) and aligned using ClustalX (Thompson et al. 1997).

Phylogenetic analyses

Phylogenetic trees of unique haplotypes were constructed using Bayesian analysis with the program MrBayes ver. 3.1 (Ronquist and Huelsenbeck 2003). MrModeltest ver. 2.2 (Nylander 2004; modified from Modeltest 3.6 (Posada and Crandall 1998)) was employed to choose the appropriate model of sequence evolution. Two independent analyses were conducted to ensure the result, every analysis consisted of two runs each containing four Markov chains that ran for $10^{7}$ generations, sampled every 1000 generations, 
Table 1 B. pewzowi samples information in this study

\begin{tabular}{|c|c|c|c|c|c|}
\hline $\begin{array}{l}\text { Locality } \\
\text { (population) } \\
\text { number and } \\
\text { sample letter }\end{array}$ & Locality & $\begin{array}{l}\text { Elevation } \\
\text { (Feet) }\end{array}$ & $\begin{array}{l}\text { Museum collection } \\
\text { voucher number / } \\
\text { Sample ID }\end{array}$ & $\begin{array}{l}\text { Haplotype } \\
\text { (This } \\
\text { paper) }\end{array}$ & $\begin{array}{l}\text { GenBank } \\
\text { Accession } \\
\text { number }\end{array}$ \\
\hline 1 & $\begin{array}{l}\text { China, Xinjiang, Tacheng; Kazak Auto. Prefecture, } \\
\text { Tacheng Dist., along Liu Su stream at Liu Su Gou, } \\
29 \text { km E of Miao'ergou Autonomous Region, R. Macey, } \\
\text { T. Papenfuss leg. }\end{array}$ & 1778 & CAS 171493 (4n199) & Hap-2 & DQ629786 \\
\hline 2 & China, Xinjiang, Aletai & 2812 & Bufo 02 & Hap-13 & EU490372 \\
\hline 3 & China, Xinjiang, Mulei & 4168 & Bufo 04 & Hap-4 & EU490374 \\
\hline 4 & China, Xinjiang, Akesu & 3601 & Bufo 09 & Hap-21 & EU490375 \\
\hline 5 & China, Xinjiang, Xinhe & 3330 & Bufo 10 & Hap-22 & EU490376 \\
\hline 6 & China, Xinjiang, Shache & 4038 & Bufo 12 & Hap-23 & EU490377 \\
\hline 7 & China, Xinjiang, Kuche & 3473 & Bufo 13 & Нар-24 & EU490378 \\
\hline 8 & China, Xinjiang, Aheqi & 5996 & Bufo 14 & Hap-25 & EU490379 \\
\hline 9 & China, Xinjiang, Pishan & 4503 & Bufo 15 & Hap-26 & EU490380 \\
\hline 10 & China, Xinjiang, Baicheng & 4047 & Bufo 16 & Нар-27 & EU490381 \\
\hline 11 & China, Xinjiang, Zepu & 4183 & Bufo 17 & Hap-17 & EU490382 \\
\hline 12 & China, Xinjiang, Yingjisha & 4241 & Bufo 18 & Hap-20 & EU490383 \\
\hline 13 & China, Xinjiang, Bohu & 3467 & Bufo 19 & Нар-28 & EU490384 \\
\hline $14 \mathrm{a}$ & China, Xinjiang, Atushi & 4263 & Bufo 20 & Hap-29 & EU490385 \\
\hline $14 b$ & & & Bufo 21 & Hap-30 & EU490386 \\
\hline 15 & China, Xinjiang, Yecheng & 4438 & Bufo 22 & Hap-21 & EU490387 \\
\hline 16 & China, Xinjiang, Hetian & 4546 & Bufo 23 & Hap-31 & EU490388 \\
\hline 17 & China, Xinjiang, Kuerle & 3067 & Bufo 24 & Hap-32 & EU490389 \\
\hline 18 & China, Xinjiang, Turpan & 0 & Bufo 25 & Hap-33 & EU490390 \\
\hline 19 & China, Xinjiang, Yuepuhu & 3963 & Bufo 26 & Hap-34 & EU490391 \\
\hline $20 \mathrm{a}$ & China, Xinjiang, Gongnaisi forestry centre & 4262 & Bufo 27 & Hap-14 & EU490392 \\
\hline $20 \mathrm{~b}$ & & & Bufo 29 & Hap-14 & EU490393 \\
\hline $20 \mathrm{c}$ & & & Bufo 30 & Hap-15 & EU490394 \\
\hline 21 & China, Xinjiang, Wenquan & 4434 & Bufo 36 & Hap-3 & EU490395 \\
\hline $22 \mathrm{a}$ & China, Xinjiang, Changji & 1883 & Bufo 38 & Hap-5 & EU490396 \\
\hline $22 b$ & $\begin{array}{l}\text { China, Xinjiang, Changji Hui Auto. Prefecture, canyon } \\
\text { above Dayou, } 8.1 \mathrm{~km} \mathrm{~S} \text { of Dayou, Tian Shan }\end{array}$ & & CAS $171676(4 \mathrm{n} 200)$ & Hap-3 & DQ629787 \\
\hline 23 & China, Xinjiang, Wushi & 4644 & Bufo 39 & Hap-35 & EU490397 \\
\hline $24 \mathrm{a}$ & China, Xinjiang, Hami & 2509 & Bufo 40 & Hap-3 & EU490398 \\
\hline $24 b$ & & & Bufo 41 & Hap-3 & EU490399 \\
\hline $24 \mathrm{c}$ & $\begin{array}{l}\text { China, Xinjiang, Hami-Barkol, Kazakh Autonomous } \\
\text { County (town), J.R. Macey, T. Papenfuss leg. }\end{array}$ & & CAS 171053 (4n197) & Hap-1 & DQ629762 \\
\hline 25 & Kazakhstan,SE,near Kokpak, & 6143 & 328 & Нар-10 & DQ629796 \\
\hline $26 \mathrm{a}$ & Kazakhstan, SE, Shalkudysu river, M. Chirikova leg. & 8180 & 327 & Hap-9 & DQ629795 \\
\hline $26 b$ & & & 329 & Hap-11 & DQ629797 \\
\hline 27 & $\begin{array}{l}\text { Kazakhstan, Altai range, environs of Terekti (formerly } \\
\text { Alexeevka) village, T. Dujsebajeva leg. }\end{array}$ & - & 302 & Hap-8 & DQ629794 \\
\hline 28 & $\begin{array}{l}\text { Kazakhstan, Altai, Pakhmanovskiye Klyuchi N boundaries } \\
\text { of S Altay range, T. Dujsebayeva leg. }\end{array}$ & - & 307 & Hap-8 & DQ629793 \\
\hline 29 & Kazakhstan, E, Tarbagataj, Tebiske river, M. Chirikova leg. & 3236 & 333 & Hap-12 & DQ629799 \\
\hline 30 & $\begin{array}{l}\text { Kazakhstan, } S \text { foothills of Altai range, Prirechnoye village, } \\
\text { T. Dujsebajeva leg. }\end{array}$ & - & 301 & Hap-7 & DQ629790 \\
\hline 31 & $\begin{array}{l}\text { China, Xinjiang Uygur Autonomous Region, Bayingolin } \\
\text { Mongol Autonomous Prefecture, Center of Tikanlik, J.R. } \\
\text { Macey, T. Papenfuss leg. } 1988\end{array}$ & - & CAS $167832(4 n 198)$ & Hap-20 & DQ629761 \\
\hline
\end{tabular}


Table 1 continued

\begin{tabular}{|c|c|c|c|c|c|}
\hline $\begin{array}{l}\text { Locality } \\
\text { (population) } \\
\text { number and } \\
\text { sample letter }\end{array}$ & Locality & $\begin{array}{l}\text { Elevation } \\
\text { (Feet) }\end{array}$ & $\begin{array}{l}\text { Museum collection } \\
\text { voucher number / } \\
\text { Sample ID }\end{array}$ & $\begin{array}{l}\text { Haplotype } \\
\text { (This } \\
\text { paper) }\end{array}$ & $\begin{array}{l}\text { GenBank } \\
\text { Accession } \\
\text { number }\end{array}$ \\
\hline $32 \mathrm{a}$ & China, Kashgar, Xinjiang, China, M. Stöck leg. & 4500 & ZSM 107/1998 (4n22) & Hap-16 & DQ629782 \\
\hline $32 b$ & & - & ZSM 108/1998 (4n23) & Нар-17 & DQ629781 \\
\hline $33 \mathrm{a}$ & $\begin{array}{l}\text { China, NW-China, Taxkurgan, E-Pamir, M. Stöck leg., } \\
\text { T. Papenfuss, J.R. Macey leg. }\end{array}$ & 11167 & ZSM 110/1998 (4n25) & Hap-18 & DQ629756 \\
\hline $33 b$ & & - & CAS 197007 (193) & Hap-18 & DQ629757 \\
\hline $33 \mathrm{c}$ & & - & CAS 197008 (194) & Hap-19 & DQ629758 \\
\hline $33 \mathrm{~d}$ & & - & CAS 197010 (196) & Hap-18 & DQ629760 \\
\hline 34 & China, E-Tien-Shan, NW-China, Xinjiang, M. Stöck leg. & 7150 & ZSM 109/1998 (4n31) & Hap-6 & DQ629785 \\
\hline 35 & China, Xinjiang, Altai, Qinghe & - & Bufo 42 & Hap-7 & EU490400 \\
\hline 36 & China, Xinjiang, Qitai, Biliu River & - & Bufo 43 & Hap-3 & EU490401 \\
\hline 37 & China, Xinjiang, Kuitun & - & Bufo 44 & Hap-2 & EU490402 \\
\hline
\end{tabular}

Locality numbers as in Fig. 1. Letters indicate multiple samples from single locality. Haplotype of each sample and elevation of each locality are given. Abbreviations: ZSM = Zoologische Staatsammlung Munich, Germany; CAS = California Academy of Sciences, San Francisco, USA

with a random starting tree, default priors and equal branch lengths. The trees corresponding to the first two million generations were discarded. Three homologous sequences of green toads from the Bufo viridis subgroup were chosen as outgroups: Bufo boulengeri (from North Africa), Bufo zugmayeri (from Pakistan: Pishin) and Bufo pseudoraddei baturae (from Pakistan: Pasu) (see Stöck et al. (2006) for nomenclature and phylogenetic trees qualifying these taxa as appropriate outgroup species).

Nested clade analyses

To detect an association between geography and haplotype frequency and to infer evolutionary processes causal for genetic structure, we conducted a nested-clade analysis (NCA; Templeton et al. 1995). First, we used the program TCS ver. 1.21 (Clement et al. 2000) to create a network of haplotypes (gaps were treated as missing data) using the 95\% statistical parsimony method of Templeton et al. (1992). The network was converted into a nested design following Templeton et al. (1987). For all clades within the network the significance levels for associations between haplotype and geography were calculated using the program GeoDis ver. 2.4 (Posada et al. 2000). Random permutation tests of the data against a null hypothesis created from a random geographic distribution of all clades within each nesting level (generated using 1,000 permutations) were used to infer association between phylogeny and geography. Significance was determined at the 5\% and $10 \%$ level. For clades, for which the null hypothesis was rejected, we followed GeoDis ver 2.4 (2004) to infer biological causes for the observed associations.

\section{Demographic analyses}

Three haplotype groups recovered by the phylogenetic analyses occupied non-overlapping geographical regions (Fig. 1) and were treated as separate units to analyze regional genetic diversity and demographic history. To understand the level of gene flow among three haplotype groups, Fst value was estimated using DNAsp ver.4.0 (Rozas et al. 2003). For comparisons of within-region genetic diversity, haplotype diversity (h) and nucleotide diversity $(\pi)$ were calculated using Arlequin ver. 2.0 (Schneider et al. 2000) and DNAsp ver.4.0 (Rozas et al. 2003). We also calculated Tajima's $D$ (Tajima 1989) and performed Fu's $F s$ test (Fu 1997) using Arlequin to confirm demographic expansions. Histograms of the frequency of observed pairwise differences among sequences were plotted using Arlequin, and the shape of the observed mismatch distribution was tested against the null hypothesis of population expansion (Slatkin and Hudson 1991). Mismatch distributions were plotted for all samples, including identical haplotypes, for each haplotype group. Populations which have gone through a period of expansion or growth are expected to have a star-like phylogeny and a unimodal shape to the mismatch distribution reflecting similarity in the amount of divergence among all pairs of haplotypes (Rogers and Harpending 1992; Slatkin and Hudson 1991). Populations which have been stable over time are predicted to have a more balanced phylogenetic shape and a bi- or multimodal mismatch distribution (Slatkin and Hudson 1991). The fit between the observed and expected distributions was tested using the sum of squared deviations (Schneider and Excoffier 1999). 
Divergence time estimates

Divergence time of $B$. pewzowi was estimated using BEAST (Drummond and Rambaut 2003; Drummond et al. 2002, 2006). The molecular clock was relaxed by allowing the rate to vary throughout the tree in an autocorrelated manner, with the rate in each branch being drawn from an exponential distribution whose mean was equal to the rate in its parent branch. Unlike previous relaxed-clock methods for rate estimation, BEAST does not require a userspecified tree topology. The model of sequence evolution used for the divergence time estimates was identical to that in the Bayesian phylogenetic analysis $(\mathrm{GTR}+\mathrm{G})$. A relaxed molecular clock model (Uncorrelated Exponential) and coalescent prior were used for the tree, and constant population size models were tested. Following a burn-in of $1,000,000$ cycles, time of the most recent common ancestor (TMRCA) were sampled once every 1000 cycles from $10,000,000$ MCMC steps. We used the conservative paleogeographic calibration from Stöck et al. (2006), who estimated the evolutionary rate of the mitochondrial D-loop in green toads as $1.278 \%$ divergence per My. Convergence of chains was checked with the program Tracer ver. 1.3 (Rambaut and Drummond 2004). The effective sample sizes for each parameter sampled from the MCMC analyses were almost always found to exceed 1000 .

\section{Results}

Partial control regions of 48 individuals from 37 populations of B. pewzowi yielded an alignment of $833 \mathrm{bp}$. We identified 42 polymorphic sites, which comprize 35 unique haplotypes. Haplotypes shared across populations were found at geographically proximate localities (Table 1, Fig. 1).

\section{Phylogenetic analyses}

A GTR + G model of evolution was selected for the Bayesian analysis by MrModeltest using the Akaike information criterion (AIC). The average standard deviations of split frequencies of two independent analyses were 0.0028 and 0.0036 , respectively. An identical branch topology was suggested by two independent analyses and is shown in Fig. 2. The Bayesian consensus tree revealed three wellsupported genetically distinct haplotype groups: (i) the EastKazakh (EK) group, (ii) the Tarim Basin (TB) group and (iii) the Dzungarian (DZ) group (Fig. 2). The posterior support values of all major haplotype groups exceeded 95 . The TB group comprises all individuals from the Tarim Basin; the

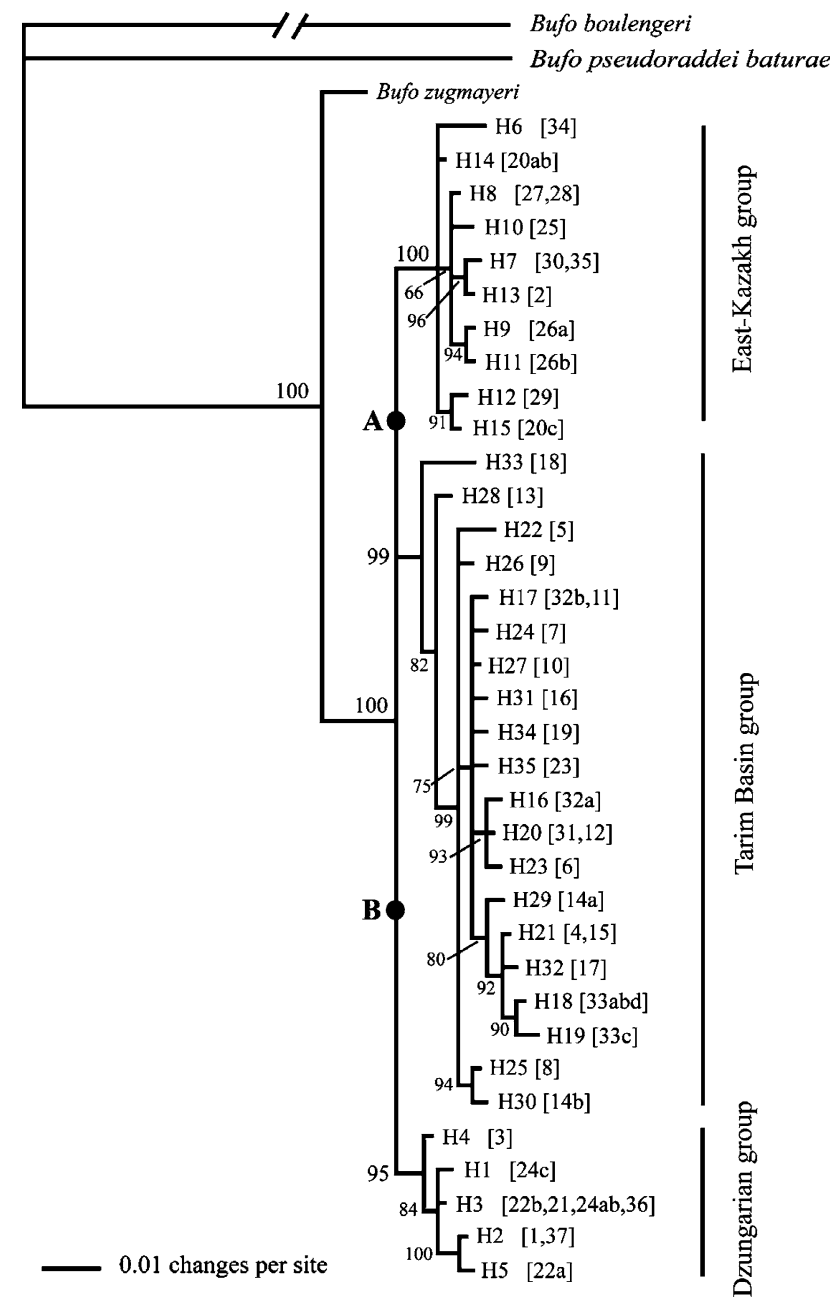

Fig. 2 Consensus tree derived from the Bayesian analysis of haplotype sequences. Posterior probabilities (greater than 50\%) for branches are shown. Locality numbers and sample IDs are given behind each haplotype. Vertical bars indicate the haplotype groups corresponding geographical distribution in Fig. 1. Point A and B illustrate positions of outgroups found when the tree was rooted with different outgroup species

DZ group mainly spans the northern slope of the Eastern Tian Shan, while the EK group is distributed in the plains and basins to the north of the Tian Shan, west and north of the Dzungarian Alatau and Tarbagatay range and south of the Altai range (Fig. 1, Table 1). In this tree, all three haplotype groups were reciprocally monophyletic. The problem of tree reconstruction and rooting is known to be challenging, especially when dealing with rapid radiations, where there is a combination of short and long branches. To further confirm our phylogenetic results, we reanalyzed our data with different outgroups. These outgroup candidates were also from the Bufo viridis subgroup, but showed different levels of divergence to the ingroup (see Stöck et al. 2006). After excluding poorly rooted trees (i.e., trees rooted with too close or too distant outgroups), we found the outgroup position to 
be unstable relative to the ingroup. When the outgroup was pinned at position A (Fig. 2), the TB group and DZ group formed a monophyletic clade with EK as a sister clade. When the outgroup point was constrained to position $\mathrm{B}$, the TB group and EK groups formed a monophyletic clade with DZ as a sister clade. However, a monophyletic clade consisting of DZ and EK group was not found in our study. Although a monophyletic clade consisting of two haplotype groups was produced in some cases, the Bayesian posterior support value of this clade was always low $(<65)$. The difficulty to find a close relationship among the three haplotype groups suggests reciprocal monophyly may most probably reflect their true phylogenetic relationship. However, more data from other rapid-evolution loci may be helpful to confirm this conclusion.

Nested clade analyses

Figure 3 shows the intraspecific network and nesting design obtained using the algorithm of Templeton et al.
(1987). One reticulation caused by an inferred haplotype connecting haplotypes H26 (loc. 9) and H14 (loc. 20) was removed (criteria of Crandall and Templeton 1993) for determining the most plausible of alternative networks. The third nesting level (clade 3-3, 3-4) illustrated the break between DZ and EK groups; clade 3-1, 3-2 described two clades within the Tarim Basin group. At the fourth nesting level one clade united haplotypes from the TB group and another included both the DZ and the EK groups. The association of the DZ and EK groups in clade 4-2 might result from relatively few mutational steps within each group as compared to the TB group. Five mutational steps are needed to connect the TB and DZ groups, while seven mutational steps are required for the connection between TB and EK. Outgroup weight calculations indicated that clade $1-5$ contained the inferred ancestral haplotype (H27, loc. 10). Haplotype H33 (loc. 18, 1-10) showed deep divergence from the rest (up to six mutational steps from its closest interior) of the TB group (clade 4-1). The null hypothesis of no association between geography and
Fig. 3 Statistical parsimony (95\%) network for 35 mitochondrial DNA haplotypes identified for Bufo pewzowi. The network is grouped into nesting clades. Each line in the network represents a single nucleotide substitution. Small circles indicate undetected intermediate haplotype states. The relative size of the boxes and ovals (at haplotype level) represent the frequency of these haplotypes (boxes around haplotypes denote those haplotypes with the highest outgroup weight). The boxes indicate nesting level (e.g., 1-4, nesting level one, grouping number four). Alphanumeric haplotype names correspond to those in Fig. 1, Table 1. Three haplotype groups corresponding to Fig. 2 are highlighted by thick-line black boxes

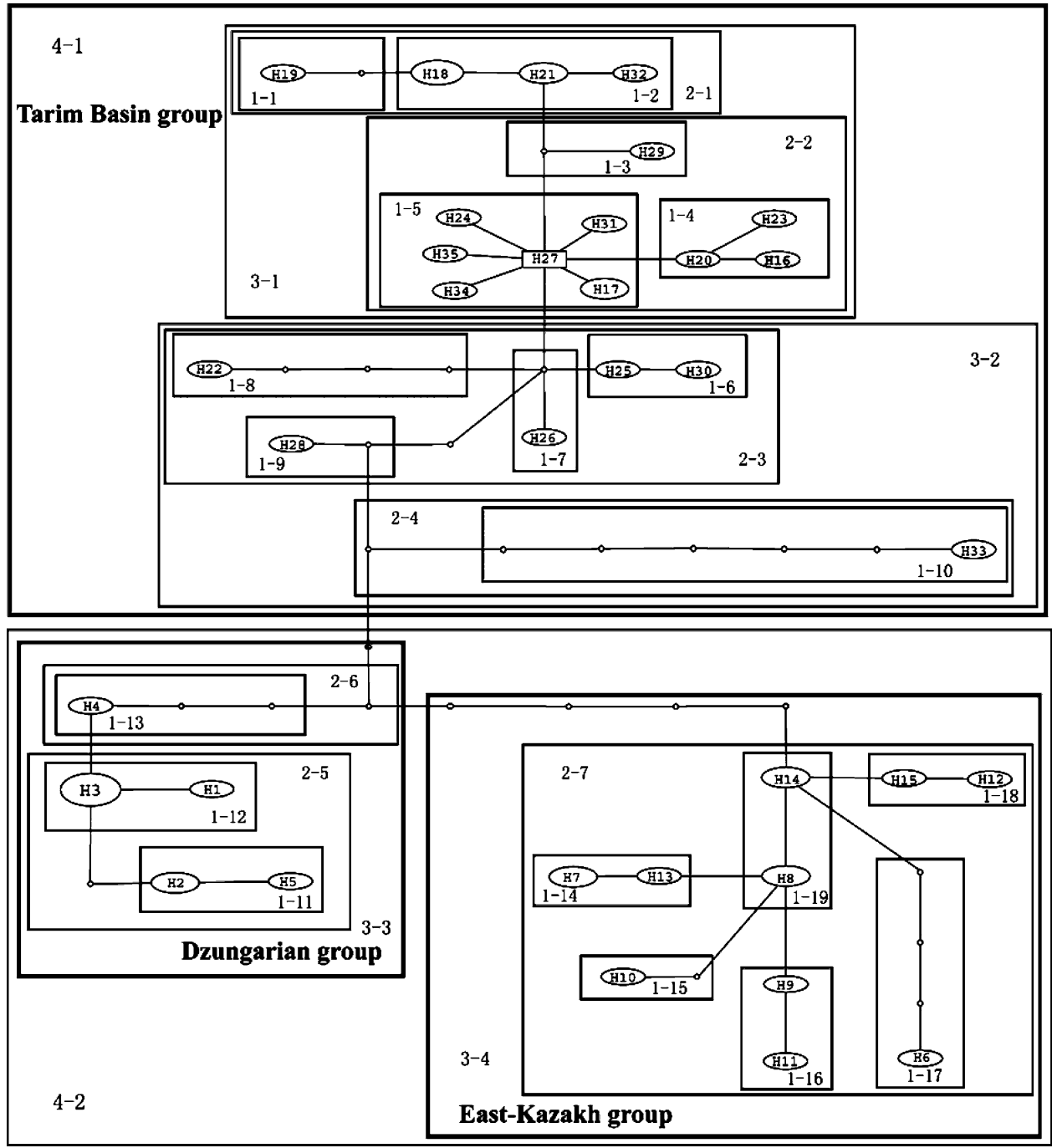


Table 2 Inference for all clades showing significant association from nested clade analysis results, using the key implemented in GeoDis ver. 2.4 (July 2004)
* The significance level of the permutational contingency test is set as $P<0.10$

\begin{tabular}{lll}
\hline Clade & Chain of inference & Inference \\
\hline Zero-step clades nested in Clade 1-2 & $1-19-20-2-3-4$ NO & $\begin{array}{c}\text { Restricted gene flow with isolation } \\
\text { by distance } \\
\text { Restricted gene flow with isolation } \\
\text { by distance }\end{array}$ \\
One-step clades nested in Clade 2-7 & $1-2-11-17-4$ NO & $\begin{array}{l}\text { Allopatric fragmentation } \\
\text { Allopatric fragmentation }\end{array}$ \\
$\begin{array}{l}\text { Three-step clades nested in Clade 4-2 } \\
\text { Four-step clades nested in entire cladogram } \\
\text { One-step clades nested in Clade 2-5* }\end{array}$ & $1-19$ NO & $\begin{array}{l}\text { Restricted gene flow with isolation } \\
\text { by distance }\end{array}$ \\
Two-step clades nested in Clade 3-1* & $1-2-3-4$ NO & $\begin{array}{l}\text { Contiguous range expansion } \\
\text { Restricted gene flow with isolation } \\
\text { byree-step clades nested in Clade 4-1* }\end{array}$ \\
\end{tabular}

haplotype position in clades was rejected for four clades (5\% significance level) and three more clades (10\%; Table 2). Nevertheless, the null hypothesis was rarely rejected in low level clades (e.g., 1-step clade) showing that sampling was partly inadequate to achieve significance (Templeton et al. 1995; Table 2), especially regarding the number of samples per location. The biological processes inferred to have caused the significant associations are listed in Table 2. Most often, restricted gene flow with isolation by distance was invoked. However, we also inferred allopatric fragmentation for splits between EK and DZ group (clade 4-2), and the TB group from both (Fig. 3).

\section{Demographic analyses}

The pairwise Fst values for the three haplotype groups were $0.6707,0.6971$ and 0.7379 respectively (Table 3 ). Levels of haplotype and nucleotide diversity were found unequal among geographic regions. Haplotype diversity $(h)$ and nucleotide diversity $(\pi)$ are significantly lower in the Dzungarian group than in the other two (Table 4). Nucleotide differences within populations are the highest in the Tarim Basin $(0.53 \%)$, followed by the E-Kazakh group $(0.40 \%)$. The Dzungarian group showed the lowest nucleotide differences $(0.22 \%)$. Between populations, nucleotide differences did not show obvious bias among the three

Table 3 Pairwise differences and Fst values between haplotype groups for the D-loop region

\begin{tabular}{llll}
\hline & DZ group & EK group & TB group \\
\hline DZ group & 0.22 & 0.7379 & 0.6707 \\
EK group & 1.02 & 0.40 & 0.6971 \\
TB group & 0.97 & 1.14 & 0.53 \\
\hline
\end{tabular}

Below diagonal: corrected average pairwise differences in percent $(\mathrm{PiXY}-(\mathrm{PiX}+\mathrm{PiY}) / 2) . P$ values for all corrected $\mathrm{PiXY}$ is 0 . Diagonal elements: pairwise differences within population (PiX). Upper diagonal: Fst values between haplotype groups groups, with an average at $\sim 1 \%$ (Table 3). Significance of neutrality tests varied depending on statistics and region. Fu's $F s$ test was highly significant for all geographic regions, whereas, Tajima's $D$ only approached significance in the Tarim Basin group $(P=0.044)$. Nevertheless, nominal values of Tajima's $D$ within the Dzungarian and E-Kazakh groups were negative, suggesting demographic expansions. Mismatch distribution analyses yielded similar results with neutral tests, all three groups showed unimodal mismatch distributions for the control region (Fig. 4). However, none of the distributions was significantly different from the null expectation of population growth (Table 4).

\section{Divergence time estimates}

We estimated that the three haplotype groups split from their most recent common ancestor 0.9 million years before present (MYBP), with a 95\% confidence interval of 0.5-1.4 MYBP. The effective sample size (ESS) for this estimation was 1695.15 from the analysis using the program BEAST.

\section{Discussion}

Our dataset is one of the few phylogeographic studies, which uses multiple sample data from widespread, small terrestrial vertebrates from Eastern Central Asia. Here, we discuss our data in context with geological and landscape history data and the few available publications from this region.

Evolutionary history of green toads in Eastern Central Asia

We found geographically isolated Tarim Basin, Dzungarian Basin and East-Kazakh haplotype groups (Fig. 2) that 
Table 4 Results of demographic parameters including $h, \pi$, Fu's $F s$, Tajima's $D$, and SSD (95\% CI and $P$-values given where applicable), grouped by geographic region

\begin{tabular}{lcrllllll}
\hline Haplogroup & $n$ & $n_{\mathrm{H}}$ & $\begin{array}{l}\text { Haplotype diversity,h } \\
( \pm 95 \% \mathrm{CI})\end{array}$ & $\begin{array}{l}\text { Nucleotide diversity, } \pi \\
( \pm 95 \% \text { CI })\end{array}$ & $\begin{array}{l}\text { Fu's } F s \\
(P \text {-value })\end{array}$ & $\begin{array}{l}\text { Tajima's } D \\
(P \text {-value })\end{array}$ & $\begin{array}{l}\text { SSD } \\
P(\text { Sim. Ssd } \geq \\
\text { Obs.Ssd })\end{array}$ \\
\hline DZ group & 10 & 5 & $0.756(0.017)$ & $0.0019(0.00044)$ & $-12.216(\mathbf{0 . 0 0 0})$ & $-0.531(0.330)$ & 0.0038 & 0.8590 \\
EK group & 13 & 10 & $0.962(0.002)$ & $0.0035(0.00054)$ & $-13.500(\mathbf{0 . 0 0 0})$ & $-0.546(0.319)$ & 0.0026 & 0.8790 \\
TB group & 25 & 20 & $0.980(0.000)$ & $0.0053(0.00079)$ & $-25.768(\mathbf{0 . 0 0 0})$ & $-1.626(\mathbf{0 . 0 4 4})$ & 0.0055 & 0.3340 \\
\hline
\end{tabular}

$n$, number of individuals

$n_{\mathrm{H}}$, number of haplotypes

$\mathrm{SSD}$, sum of squared deviations of mismatch distribution from prediction under population expansion mode

Significance $P$-value in bold face

Fig. 4 Mismatch histograms for the control region. Observed pairwise substitutional differences (grey boxes) are compared with values simulated under a population expansion model (black line with dots). Details in text
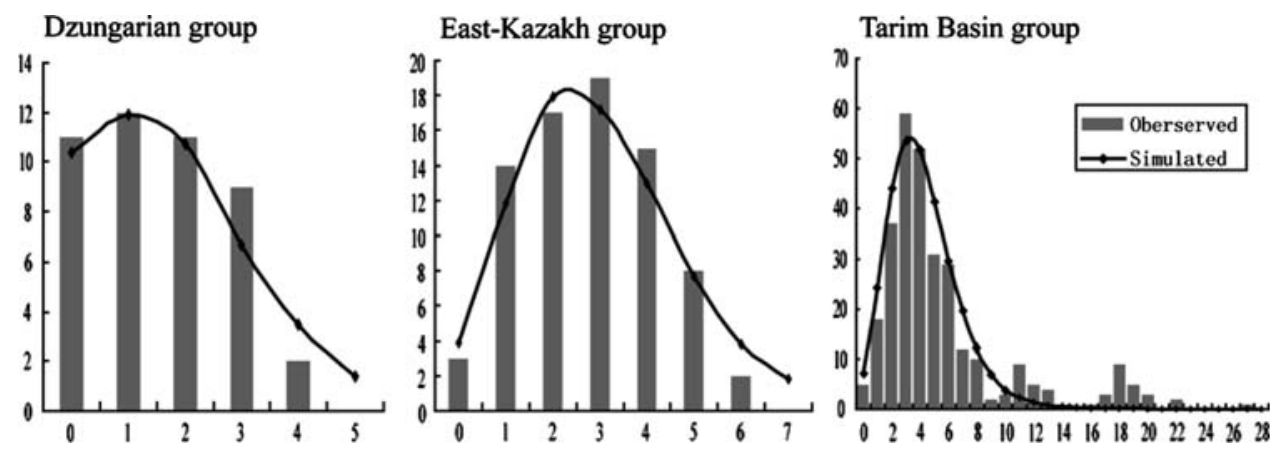

appear divided by the Tian Shan, Dzungarian Alatau and Tarbagatay ranges (Fig. 1). As expected for amphibians (e.g., Hoffman and Blouin 2004; Shaffer et al. 2004), the genetic structure of $B$. pewzowi shows a strong phylogeographic signature. The phylogeny exhibits a polytomy containing three very well supported monophyletic haplotype groups and suggests a vicariant event (or serial events within a short period of time) split B. pewzowi into these lineages. This finding rejects a very recent invasion of the Tarim Basin (hypothesis 1). Instead, the phylogenetic structure suggests that green toads survived in glacial refugia and spent there sufficient periods of time to form three distinct groups.

The Tian Shan lies in the actively deforming part of the India-Asia collision zone, which is regarded as one of the most active geological areas. Through crustal shortening and thickening caused by the India-Asia collision, the Tian Shan underwent uplifting in four main ages: about 65.6, 45.22 and $32.60 \mathrm{Ma}$ (initial uplift), and between 24.74 and 15.98 Ma, 6.7-0.73 Ma and less than 0.73 Ma (Liu et al. 2004; see also Yang and Liu 2002). Stöck et al. (2006) estimated that the single mitochondrial lineage that lead to all Central Asian taxa of the B. viridis subgroup (eastern Iran to western Mongolia, including $B$. pewzowi), diverged in the Pliocene (between 4.4 and 3.1 Mya) from proximate toads in Anatolia. In our study, inferences from NCA for all groups (the entire network) and clade 4-2 (EK and DZ group) suggested allopatric fragmentation caused by topography. In accordance to the occurrence of three reciprocally monophyletic groups (Fig. 2), we favor a vicariant rather than a dispersal event to have shaped the phylogeographic structure of $B$. pewzowi. Divergence time estimation suggested that different lineages of $B$. pewzowi diverged from their most recent common ancestor at ca. 0.9 Mya, which corresponds to the end of the third uplifting time intervals (6.7-0.73 Mya) of the Tian Shan (Liu et al. 2004). We inferred (NCA) that H27 (loc. 10) was the ancestral haplotype in the Tarim Basin, suggesting toads may have first reached the basin from the north of the Tian Shan or were forced into a glacial refugium in this region. Therefore, we propose a scenario on the biogeographic history of $B$. pewzowi comprising three stages: (i) the lineage to $B$. pewzowi reached eastern Central Asia before the Quaternary mountain building and Pleistocene cooling and aridization, perhaps in the late Pliocene ( $3 \mathrm{Ma}$ ). (ii) Toads may have entered the Tarim Basin across western mountain passes from the currently nonsampled Fergana valley, or reached the Tarim along the Tian Shan foothills from the north. Few founders may have surmounted the passes near the Turpan basin to the north and gave rise to the Dzungarian group; to the northeast they likely spread along the western foothills of the Dzungarian Alatau and further occupied the upper margin of the Dzungarian Basin. At that time, there was perhaps still 
gene flow among populations. (iii) The advance of Pleistocene cooling and aridization accompanied by PlioPleistocene mountain building in the Tian Shan until $\sim 2.58 \mathrm{Ma}$ (Sun et al. 2004) and adjacent mountain ranges restricted genetic contact increasingly until populations were isolated into different regions, perhaps in lower or middle Pleistocene (1.8-1 Ma).

Strong restriction of gene flow between haplotype groups was suggested by both $F s t$ values and NCA. The $F s t$ values between regions were high (0.67-0.74), suggesting a barrier effect of the Tian Shan, most probably along with cooling and aridization during glacial periods of the Pleistocene that disrupted the gene flow. This is also supported by a lack of shared haplotypes between ranges of the three clades (one exception). Interestingly, a Dzungarian haplotype from TaCheng (loc. 1) in the range of the EKazakh group (Fig. 1) suggests a westward dispersal of Dzungarian haplotypes. Both ranges appear connected via the Dzungarian Gate (ca. 45.25 N; 82.50 E). 'Restricted gene flow with isolation by distance' was inferred for the highest level clade of each haplotype groups by NCA (Table 2), suggesting the difficulty of genetic connection through the range of each group. Furthermore, restricted gene flow within a one-step clade (1-2) nested in TB group was also detected. The basal branch of the TB clade, haplotype H33 from Turpan depression (loc. 18) and H28 (loc. 13), showed notable divergence from the remaining ones, suggesting the genetic contact to other regions of the Tarim Basin has been disrupted for a large number of generations. A gecko of the genus Teratoscincus occurring in the Turpan depression (Macey et al. 2005) seems to show similar phylogeographic isolation but may have persisted in Turpan much longer periods of time.

The widely distributed TB group reflects the relative ecological connectivity of the Tarim river drainage and its tributaries. The climate in the Tarim Basin may have been mostly arid since the Tertiary; however, an episodically connected ring of natural oasises along the foothills of the surrounding high mountains was probably developed throughout Tertiary and Quaternary (Zhang et al. 2003). In addition, more recent humid periods and changing river flow from west to east (and vice versa, Zhang et al. 2003) and a river (Keriya), crossing the basin's Taklamakan desert centrally from the south to the northern Tarim river as recently as during the Chinese Xihan dynasty ( 200-25 B.C.; Yang et al. 2002), probably contributed to dispersal of some green toads while others persisted in temporarily isolated oasises.

Demographic history and Pleistocene signatures

Demographic analyses show evidence of both population expansions and historical bottlenecks that are likely caused by Pleistocene glacial oscillations. A recent growth of the Tarim Basin group is indicated by significant negative value of Fu's $F s$ and Tajima's $D$ (Table 4), as well as unimodal mismatch distributions (Fig. 4, Table 2). We also deduced this from the star-like haplotype network (clade 15 in clade 3-1, Fig. 3). In the Dzungarian group, recent range expansion is suggested only by Fu's $F s$ test and the unimodal mismatch distribution curve; this ambiguity may result from a relatively short expansion time. Demography of the E-Kazakh is similar to the DZ group (Table 4). However, a star-like haplotype network in clade 2-7 (Fig. 3) shows a stronger signature of range expansion in the E-Kazakh one, consistent with a stronger glacial retreat and a recent postglacial expansion in this region.

Loss of alleles and homozygosity are consequences of founder events from postglacial expansions (Hewitt 2000). Our analyses suggested that the northern Dzungarian region was most affected followed by the E-Kazakh region, and as expected the southern Tarim Basin region was least affected. The pairwise differences within DZ, EK and TB groups were $0.22 \%, 0.40 \%$ and $0.53 \%$ respectively (Table 3). A similar pattern was found for haplotype diversity (h) and nucleotide diversity ( $\pi$ ) (Table 4 ).

Genetic differentiation triggered by the Tian Shan has been reported from several animal species, such as red deer (Cervus elaphus), gekkonid (Teratoscincus) and agamid lizards (Phrynocephalus) (Mahmut et al. 2002; Ludt et al. 2004; Macey et al. 1999, 2005; Pang et al. 2003), with the major vicariant events estimated to be of Late Miocene or Pliocene age (Macey et al. 1999, 2005; Pang et al. 2003). By implication, vicariant groups had to survive the Pleistocene glacial cycles in the basins north and south of the Tian Shan that must have played key roles as glacial refugia for relatively cold-tolerant species. Accordingly, Guo and Wang (2007) considered the Tarim and Dzungarin Basins "secondary divesification centers" for Phrynocephalus lizards. However, glacial refugia and post-glacial expansion patterns of Eastern Central Asia have been rarely investigated. In our study, the haplotype network suggests glacial refugia for each of the three major lineages. During glacial advance, distribution ranges of species were restricted to refugia. Since refugia served as sources of post-glacial expansions, haplotypes harbored here are supposed to be older than derived ones emerging during colonization. In the haplotype network, inferred ancestral haplotypes have a strong tendency to be immediately interior to derived ones (Templeton 1998). Hence, these interior haplotypes have a high probability to be localized in refugia, especially those in the center of a starlike radiation. Therefore, we conclude that last-glacial maximum (LGM) refugia were perhaps situated in the Changji region (loc. 22) of the DZ group (see Fig. 1). Two potential separate refugia were inferred at the foot of the 
Tian Shan (Gongnaisi, loc. 20) and at the Altai range (Terekti, loc. 27, 28) of the EK group and in the Turpan depression (loc. 18) for the TB group. In the Changji region, identical haplotypes (H3) were found in four populations (loc. 22, 21, 24, 36), partly as distantly as $1,100 \mathrm{~km}$. This suggests rapid expansions into available habitats immediately after the glacial maximum. However, Rhode et al. (1996) found a late Pleistocene humid episode (radiocarbon-dated at 37,000-32,000 year B.P.) in Dzungaria. Although this first wet episode was followed by a period of extreme aridity (LGM), the Early-Mid Holocene record again indicates conditions wetter than today. Such wetter periods provided climatic conditions that may have facilitated green toad dispersal, and may explain our data of a rapid expansion of the toads. An inferred refugium in the Altai range (Terekti, loc. 27, 28) may have been crucial for the maintenance of the EK lineage and its rapid colonization of higher latitudes after the last glaciation. In this case, toads that survived here may have undergone a fast post-LGM recolonization to the Tarbagatay range and southern Altai range. The postglacial expansion from the Turpan refugium was apparently restricted to the basin, as proximate populations showed significant genetic distance (e.g., loc.13, 36).

Our data on green toads refer to glacial refugia and may be especially significant to identify regions with seasonally available liquid water (for reproduction of toads). The observed distribution patterns within each green toad lineage may result from fragmentation, contraction and subsequent expansion of populations associated with the glacial and interglacial cycles. From these refugia, lineages re-expanded and spread in the basins as the Tarim Basin, Dzungaria and the region west and north of the Tarbagatay range and south of the Altai. To verify if these data for the region are of general significance for other species will be a challenging future research topic.

\section{Taxonomic implications}

Stöck et al. (2001) provided information on name-bearing types, type localities, nomenclatural and systematic histories, morphology, ploidy level, bioacoustics, distribution, proposed current taxonomic status, and a tentative identification key. Seven nominal taxa (for details Stöck et al. 2001) have been described in the geographic scope of our study. If one likes to apply subspecific names, we note on the haplotype groups found that: (1) The Tarim Basin group represents the nominotypical subspecies Bufo pewzowi pewzowi (Bedriaga 1898). (2) The restricted type locality of $B$. pewzowi strauchi (Bedriaga, 1898) to the "lower reaches of Tarim" by Stöck et al. (2001) is covered by this range, making this name (strauchi) a junior subjective synonym of the B. p. pewzowi. The same synonymy fits to the nominal subspecies Bufo pewzowi taxkorensis (Fei et al. 1999), a tetraploid form as shown by Stöck et al. (2001) that is deeply nested with the TB clade (Bufo pewzowi pewzowi). (3) The E-Kazakh group could be termed Bufo pewzowi unicolor (Kashchenko 1909), however, as Stöck et al. (2006) have shown, the mtDNA phylogeny of this group is intertwined with that of diploid Bufo turanensis (Hemmer et al. 1978) and does not fit into classical nomenclatural concepts (cf. Litvinchuk et al. 2006). Further research is ongoing to better understand the interaction between diploid and tetraploid green toads in this region. (4) Taxonomic proposals of Stöck et al. (2001) for Bufo nouettei (Mocquard 1910) and Bufo tianschanicus (Toktosunov 1984) were supported by our analyses, making both junior subjective synonyms of Bufo pewzowi.

Acknowledgements We are indebted to HESEN Abdureyim (XinJiang Normal University), J. Robert Macey and Theodore J. Papenfuss (University of California, Berkeley) for collecting many samples from Xinjiang and to Tatjana Dujsebayeva and Marina Chirikova (Almaty Institute of Zoology, Laboratory of Ornithology and Herpetology) for providing some samples from East Kazakhstan. We would like to thank Xiao-Hong Chen and Yi-Ling Chen for technical assistance, Qiao-Juan Huang for help with DNA sequencing, a reference from Christoph Muster (University of Leipzig), and two anonymous reviewers for their helpful comments. This research is supported by the National Natural Science Foundation of China (No. 30771151) and the funds from the Ministry of Education of China (No. IRT0447) to L.-H. Qu. This work was also in part supported by a research fellowship (Sto 493/1-2) from the Deutsche Forschungsgemeinschaft (DFG) to M. Stöck and the University of California, Berkeley (Craig Moritz and David Wake).

\section{References}

Aubekerov B, Gorbunov A (1999) Quaternary permafrost and mountain glaciation in Kazakhstan. Permafr Periglac Processes 10:65-80

Bedriaga JV (1898) Wissenschaftliche Resultate der von N. M. Prezewalski unternommenen Reisen. Zoologischer Theil. vol. III, part 1. Amphibien und Reptilien. Kaiserliche Akademie der Wissenschaften, 1st edn., St. Petersburg

Borkin LY (1999) Distribution of amphibians in North Africa, Europe, and the former Soviet Union. In: Duellman WE (ed) Patterns of distribution of Amphibians. John Hopkins University press, Baltimore, London, pp 329-420

Clement M, Posada D, Crandall KA (2000) TCS: a computer program to estimate gene genealogies. Mol Ecol 9:1657-1659

Crandall KA, Templeton AR (1993) Empirical tests of some predictions from coalescent theory with applications to intraspecific phylogeny reconstruction. Genetics 134:959-969

Drummond AJ, Rambaut A (2003) BEAST. Version 1.3. Oxford University Press, Oxford. http://evolve.zoc.ox.ac.uk/beast/

Drummond AJ, Nicholls GK, Rodrigo AG, Solomon W (2002) Estimating mutation parameters, population history and genealogy simultaneously from temporally spaced sequence data. Genetics 161:1307-1320 
Drummond AJ, Ho SYW, Phillips MJ, Rambaut A (2006) Relaxed phylogenetics and dating with confidence. PLoS Biol 4:699-710

Ehlers J, Gibbard PL (eds) (2004) Quaternary glaciations, extent and chronology, part III: South America, Asia, Africa, Australasia, Antarctica. Series: development in quaternary science 2. Rose J, (ed) Elsevier, Amsterdam

Fei L, Ye CY, Huang YZ, Chen XN (1999) Taxonomic studies on Bufo viridis from west China (Amphibia: Anura). Zool Res 20:294-300

Fu YX (1997) Statistical tests of neutrality of mutations against population growth, hitchhiking and background selection. Genetics 147:915-925

Goebel AM, Donnelly JM, Atz ME (1999) PCR primers and amplification methods for $12 \mathrm{~S}$ ribosomal DNA, the control region, cytochrome oxidase I, and cytochromebin bufonids and other frogs, and an overview of PCR primers which have amplified DNA in amphibians successfully. Mol Phylogenet Evol 11:163-199

Guo X, Wang Y (2007) Partitioned Bayesian analyses, dispersalvicariance analysis, and the biogeography of Chinese toadheaded lizards (Agamidae: Phrynocephalus): a re-evaluation. Mol Phylogen Evol 45:643-662

Hemmer H, Schmidtler JF, Böhme W (1978) Zur Systematik zentralasiatischer Grünkröten (Bufo viridis - Komplex) (Amphibia, Salientia. Bufonidae). Abh Staatl Mus Tierkd Dresden 34:349-384

Hewitt G (2000) The genetic legacy of the quaternary ice ages. Nature 405:907-913

Hewitt GM (2004) Genetic consequences of climatic oscillations in the Quaternary. Trans R Soc Lond, B, Biol Sci 359:183-195

Hewitt GM (2007) Holarctic phylogeography and quarternary biogeography. A synthesis. In: 3rd international biogeography society conference, Tenerife, January 9-13, 2007, p 36

Hoffman EA, Blouin MS (2004) Evolutionary history of the northern leopard frog: reconstruction of phylogeny, phylogeography, and historical changes in population demography from mitochondrial DNA. Evolution 58:145-159

Kashchenko NF (1909) Gady, sobrannye sredneaziatskimi ekspediciami prof. V. V. Sapozhnikova v. 1902-1906 i. $1908 \mathrm{gg}$. Ezhegognik Zoolog. Muz. imp. Akad. 14:119-130 (in Russian)

Lehmkuhl F. MK, Strauch G (2004) The extent of Late Pleistocene glaciations in the Altai and Khangai mountains. In: Ehlers J, Gibbard PL (eds) Quaternary glaciations, extent and chronology, part III: South America, Asia, Africa, Australasia, Antarctica. pp 243-254. Series: Development in Quaternary Science 2, Rose J, ed. Elsevier, Amsterdam

Litvinchuk SN, Rozanov YM, Usmanova NM, Borkin LY, Mazanaeva LF, Kazakova VI (2006) Variability of microsatellites BM224 and Bcal7 in populations of green toads (Bufo viridis complex) differing by nuclear DNA content and ploidy. Tsitologia 48:332-345 [original in Russian]

Liu W, Lathrop A, Fu J, Yang D, Murphy RW (2000) Phylogeny of East Asian bufonids inferred from mitochondrial DNA sequences (Anura: Amphibia). Mol Phylogenet Evol 14:423-435

Liu Y, Wang ZX, Jin X, Li T, Li Y (2004) Evolution, chronology and depositional effect of uplifting in the eastern sector of the Tian shan Mountains. Acta Geologica Sinica 78:319-331

Ludt CJ, Schroeder W, Rottmann O, Kuehn R (2004) Mitochondrial DNA phylogeography of red deer (Cervus elaphus). Mol Phylogenet Evol 31:1064-1083

Macey JR, Wang Y, Ananjeva NB, Larson A, Papenfuss TJ (1999) Vicariant patterns of fragmentation among gekkonid lizards of the genus Teratoscincus produced by the Indian collision: a molecular phylogenetic perspective and an area cladogram for Central Asia. Mol Phylogenet Evol 12:320-332

Macey JR, Fong JJ, Kuehl JV et al (2005) The complete mitochondrial genome of a gecko and the phylogenetic position of the
Middle Eastern Teratoscincus keyserlingii. Mol Phylogenet Evol 36:188-193

Mahmut H, Masuda R, Onuma M, Takahashi M, Nagata J, Suzuki M, Ohtaishi N (2002) Molecular phylogeography of the red deer (Cervus elaphus) populations in Xinjiang of China: comparison with other Asian, European, and North American populations. Zool Sci 19:485-495

Mocquard F (1910) Voyage de M. le Dr. Louis Villant dans l'Asie centrale (Mission Pelliot). Bull Mus Hist Paris 16:145-153

Nevo E, Dessauer HC, Kuo Chian C (1975) Genetic variation as a test of natural selection. Proc Natl Acad Sci USA 72:2145-2149

Ning Sh-L, Zhou L-Z, Zhang B-W, Zhao T-B, Zou G-Y (2007) Phylogeography patterns of the great gerbil Rhombomys opimus in China based on mitochondrial cytochrome $b$ gene sequence variations. Acta Zool Sinica 53:630-640

Nylander J (2004) MRMODELTEST (version 2). Program distributed by the author. Evolutionary Biology Centre, Uppsala University

Pang J, Wang Y, Zhong Y, Hoelzel R, Papenfuss TJ, Zeng X, Ananjeva NB, Zhang YP (2003) A phylogeny of Chinese species in the genus Phrynocephalus (Agamidae) inferred from mitochondrial DNA sequences. Mol Phylogenet Evol 27:398-409

Petit RJ, Aguinagalde I, De Beaulieu JL et al (2003) Glacial refugia: hotspots but not melting pots of genetic diversity. Science 300:1563-1565

Posada D, Crandall KA (1998) MODELTEST: testing the model of DNA substitution. Bioinformatics 14:817-818

Posada D, Crandall KA, Templeton AR (2000) GeoDis: a program for the cladistic nested analysis of the geographical distribution of genetic haplotypes. Mol Ecol 9:487-488

Rambaut A, Drummond AJ (2004) Tracer. University of Oxford, Oxford

Rhodes TE, Gasse F, Lin R et al (1996) A Late Pleistocene-Holocene lacustrine record from Lake Manas, Zunggar (northern Xinjiang, western China). Palaeogeogr Palaeoclimatol Palaeoecol 120:105-121

Rogers AR, Harpending H (1992) Population growth makes waves in the distribution of pairwise genetic differences. Mol Biol Evol 9:552-569

Ronquist F, Huelsenbeck JP (2003) MrBayes 3: Bayesian phylogenetic inference under mixed models. Bioinformatics 19:1572-1574

Rozas J, Sanchez-DelBarrio JC, Messeguer X, Rozas R (2003) DnaSP, DNA polymorphism analyses by the coalescent and other methods. Bioinformatics 19:2496-2497

Sambrook J, Fritsch FF, Maniatis T (1989) Molecular cloning, a laboratory manual. Cold Springs Harbor Laboratory Press, Plainview, NY

Schneider S, Excoffier L (1999) Estimation of past demographic parameters from the distribution of pairwise differences when the mutation rates vary among sites: application to human mitochondrial DNA. Genetics 152:1079-1089

Schneider S, Roessli D, Excoffier L (2000) Arlequin ver. 2.000: a software for population genetic data analysis Genetics and Biometry Laboratory, University of Geneva, Switzerland

Shaffer HB, Fellers GM, Randal Voss S, Oliver JC, Pauly GB (2004) Species boundaries, phylogeography and conservation genetics of the red-legged frog (Rana aurora/draytonii) complex. Mol Ecol 13:2667-2677

Shi YF (2002) A suggestion to improve the chronology of quaternary glaciations in China. J Glaciol Cryopedol 24:687-692

Shimodaira H, Hasegawa M (2001) CONSEL: for assessing the confidence of phylogenetic tree selection. Bioinformatics 17:1246-1247

Slatkin M, Hudson RR (1991) Pairwise comparisons of mitochondrial DNA sequences in stable and exponentially growing populations. Genetics 129:555-562 
Stöck M, Günther R, Böhme W (2001) Progress towards a taxonomic revision of the Asian Bufo viridis group: current status of nominal taxa and unsolved problems (Amphibia: Anura: Bufonidae). Zool Abh Staatl Mus Tierkunde Dresden 51:253-319

Stöck M, Steinlein C, Lamatsch DK, Schartl M, Schmid M (2005) Multiple origins of tetraploid taxa in the Eurasian Bufo viridis subgroup. Genetica 124:255-272

Stöck M, Moritz C, Hickerson M, Frynta D, Dujsebayeva T, Eremchenko V, Macey JR., Papenfuss TJ, Wake DB (2006) Evolution of mitochondrial relationships and biogeography of Palearctic green toads (Bufo viridis subgroup) with insights in their genomic plasticity. Mol Phylogenet Evol 41:663-689

Sun J, Zhu R, Bowler J (2004) Timing of the Tianshan Mountains uplift constrained by magnetostratigraphic analysis of molasse deposits. Earth Planet Sci Lett 219:239-253

Taberlet P, Fumagalli L, Wust-Saucy AG, Cosson JF (1998) Comparative phylogeography and postglacial colonization routes in Europe. Mol Ecol 7:453-464

Tajima F (1989) Statistical method for testing the neutral mutation hypothesis by DNA polymorphism. Genetics 123:585-595

Templeton AR (1998) Nested clade analyses of phylogeographic data: testing hypotheses about gene flow and population history. Mol Ecol 7(4):381-397. Review

Templeton AR, Boerwinkle E, Sing CF (1987) A cladistic analysis of phenotypic associations with haplotypes inferred from restriction endonuclease mapping. I. Basic theory and an analysis of alcohol dehydrogenase activity in Drosophila. Genetics 117:343-351

Templeton AR, Crandall KA, Sing CF (1992) A cladistic analysis of phenotypic associations with haplotypes inferred from restriction endonuclease mapping and DNA sequence data. III. Cladogram estimation. Genetics 132:619-633

Templeton AR, Routman E, Phillips CA (1995) Separating population structure from population history: a cladistic analysis of the geographical distribution of mitochondrial DNA haplotypes in the tiger salamander, Ambystoma tigrinum. Genetics 140:767-782

Thompson JD, Gibson TJ, Plewniak F, Jeanmougin F, Higgins DG (1997) The ClustalX windows interface: flexible strategies for multiple sequence alignment aided by quality analysis tools. Nucleic Acids Res 24:4876-4882

Toktosunov AT (1984) Ecological basis of altitude adaptation of the vertebrates of Tian-Shan. Nauka Publ. House. Leningrad. (in Russian)

Wang Y, Fu J (2004) Cladogenesis and vicariance patterns in the toad-headed lizard Phrynocephalus versicolor species complex. Copeia 2004:1999-1206

Yang X, Zhu Z, Jaekel D, Owen LA, Han J (2002) Late quaternary palaeoenvironment change and landscape evolution along the Keriya River, Xinjiang, China: the relationship between high mountain glaciation and landscape evolution in foreland desert regions. Q Int 97-98:155-166

Yang Y, Liu M (2002) Cenozoic deformation of the Tarim plate and the implications for mountain building in the Tibetan Plateau and the Tian Shan. Tectonics 21:1069

Yin A, Harrison TM (2000) Geologic evolution of the HimalayanTibetan orogen. Annu Rev Earth Planetary Sci 28:211-280

Zhang H, Wu JW, Zheng QH, Yu YJ (2003) A preliminary study of oasis evolution in the Tarim Basin, Xinjiang, China. J Arid Environ 55:545-553 